\title{
System Dynamics and Learning: Learning During the Product Realization Chain
}

\author{
Anna P. Chatzimichali, Vassilios D. Tourassis \\ Department of Production Engineering and Management \\ Democritus University of Thrace, Xanthi, Greece \\ axatzimi@pme.duth.gr, vtourasi@pme.duth.gr
}

\begin{abstract}
Global market competition and consumer attitudes, demand a constant flow of new products in the market. Product lifecycles shrink and consequently the pressure for novel products that rapidly pass from the $R \& D$ lab to the consumer hands is increased, especially for high-technology firms. This requires particularly high rates of learning allowing firms to develop new products faster and adapt quickly to market changes. This paper addresses a gap in the learning literature, presenting an integrative model for learning during the whole process of new product development, from concept design to actual manufacturing. Higher order learning dynamics, occurring during the product realization chain (product design, process modeling, process execution) are combined with the learning curve theory, in order to present an innovative view of learning that facilitates the modeling of this complex process through control theory.
\end{abstract}

Keywords - product realization chain, learning curve theory, new product development

\section{INTRODUCTION}

During new product development, product design and process design rely heavily on the richness of knowledge and information available. Learning is a fundamental process that underlies and coordinates these initial stages. Furthermore, learning is present when building on existing knowledge, a manufacturing process progressively reaches full production capacity and a steady state.

Learning is a function ubiquitous at these early stages of development. However, it is particularly difficult to model and quantify the overall process of new product development through the traditional approach of learning curve theory. Learning curves have long been used as tools to measure learning [1]. Irrespective of the area of application, the theory of learning curve attempts to describe the evolution over time of the pertinent parameter through a single, typically exponential, function. Extensive data fitting is then employed to estimate the assumed constant rate of increase. Nevertheless, their main drawback is that they only model learning through production cost, or production time; measures unable to quantify the rich dynamics of new product development.

Considered in this light, we approach learning during new product development as a series of individual learning blocks; the blocks of the product realization chain. Product realization chain that evolves along the product design, the process modeling and the process execution functions, provides a basic structure to model the learning phenomenon, by utilizing basic systems theory.

Additionally, while existing literature in new product development has been focused either the on the very early stages of product/concept development [2], or on the manufacturing ramp-up [3], [4], we propose a more holistic approach of learning that incorporates all previous stages. Furthermore, we present a case study of this framework on Apple's IPod realization chain to clarify further this concept.

\section{THE PRODUCT REALIZATION CHAIN}

Considering that performance improvement and learning during new product development is not an event or a snapshot, we present an integrated framework on how processes progressively built results in practice. The product realization chain models the basic functions of new product development and evolves along three distinct functions, the product design, the process modeling and the process execution.

\section{A. Product Design}

The first function is product design, during which designers explore and evaluate potentially useful concepts. The most promising concepts are elaborated, the specifications of the product are defined, working models of design alternatives are built and prototypes of the final product are developed. At this stage Axiomatic Design, Design for $\mathrm{X}$ or Design for Manufacturing methods are used. A recent literature review in product design methodologies can be found in [5].

Some of these tools aim to increase the product manufacturability and incorporate manufacturing issues into the design process. However, they usually provide design options that the manufacturing department passively follows, by translating the physical materials of the product to instructional information.

\section{B. Process Modelling}

Process modeling "translates product design into technical knowledge, organizational capabilities and operating processes needed to create the product" [6]. During this stage, process engineers address the concerns about how a new product design impacts on the execution of a process, and take initiatives to prepare for upcoming product design releases or changes. However, there is a gap in knowledge concerning process development. Usually, process development is either ignored or mixed with product development in existing 


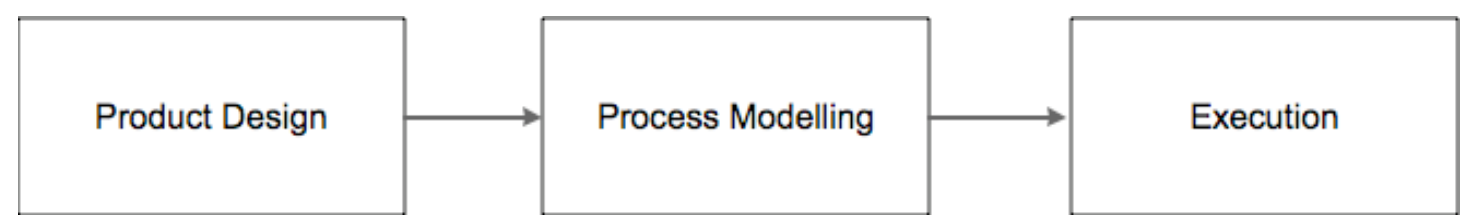

Figure 1. Product realization chain

empirical and theoretical reports [7]. Although the practice of decoupling product design and process development is common in many industries such as automobile assembly [8] as well as PCBA industry [9].

\section{Process Execution}

Finally, the last stage is the execution of the production process, when the manufacturing and the processes are on. This phase translates all instructional information and specifications from the previous two phases into action. Consequently, the real experience of production catalyzes errors, defects or mistakes and triggers production yield. During this period the manufacturing process is making the transition from zero to full-scale production and is also known as production ramp-up [3], [4].

\section{IS LEARNING A LINEAR SYSTEM?}

Learning curves have been widely used over the years to model not only individual learning, but also learning in whole production system. For this reason many learning models have been suggested that vary according to the approach and the application.

TABLE I. LEARNING CURVE MODELS

\begin{tabular}{|l|l|c|}
\hline \multicolumn{1}{|c|}{$\begin{array}{c}\text { Learning Curve } \\
\text { models }\end{array}$} & \multicolumn{1}{|c|}{ Models and Number of Parameters } \\
\cline { 2 - 3 } Hyperbolic -2 & $\mathrm{y}=\mathrm{k}\left(1-\mathrm{e}^{-\mathrm{x} / \mathrm{r}}\right)$ & 2 \\
\hline Hyperbolic -3 & $\mathrm{y}=\mathrm{k}[(\mathrm{x}+\mathrm{p}) /(\mathrm{x}+\mathrm{p}+\mathrm{r})]$ & 3 \\
\hline Exponential -2 & $\mathrm{y}=\mathrm{k}(1-\mathrm{e}-\mathrm{x} / \mathrm{r})$ & 2 \\
\hline Exponential -3 & $\mathrm{y}=\mathrm{k}\left(1-\mathrm{e}^{-(\mathrm{x}+\mathrm{p}) / \mathrm{r}}\right)$ & 3 \\
\hline Power Law - Wright & $\mathrm{y}=\mathrm{C}_{1} \mathrm{x}^{-\mathrm{b}}$ & 2 \\
\hline S Curve & $\mathrm{y}=\mathrm{C}_{1}\left[\mathrm{M}+(1-\mathrm{M})(\mathrm{x}+\mathrm{B})^{-\mathrm{b}}\right]$ & 4 \\
\hline Time Constant & $\mathrm{y}=\mathrm{y}_{\mathrm{c}}+\mathrm{y}_{\mathrm{f}}\left(1-\mathrm{e}^{-\mathrm{w} / \mathrm{\tau}}\right)$ & 3 \\
\hline DeJong & $\mathrm{y}=\mathrm{C}_{1}\left[\mathrm{M}+(1-\mathrm{M}) \mathrm{x}^{-\mathrm{b}}\right]$ & 3 \\
\hline Stanford $\mathrm{B}$ & $\mathrm{y}=\mathrm{C}_{1}(\mathrm{x}+\mathrm{B})^{-\mathrm{b}}$ & 3 \\
\hline Knecht & $\mathrm{y}=\mathrm{C}_{1} \mathrm{x}^{\mathrm{b}} \mathrm{e}^{\mathrm{cx}}$ & 3 \\
\hline Levy & $\mathrm{y}=\mathrm{P}\left(1-\mathrm{e}^{-(\mathrm{a}+\mathrm{\mu x})}\right)$ & 4 \\
\hline
\end{tabular}

Table 1 briefly presents several common learning curve models. While not intended to present an exhaustive list of learning models used over the years in the literature, the table reviews some representative forms of learning to provide a concise outline.
However, none of these models can be considered linear. According to systems theory a system is considered linear when it satisfies both the conditions of Additivity and Homogeneity. Additivity is satisfied if the summary of inputs results in the summary of outputs, while homogeneity if the input scaled by a certain factor produces an output scaled by that same factor.

Consequently, an interesting question arises; can we model learning during the product realization chain as a control system?

In the next section we discuss each product realization stage individually and present a theoretical framework able to model performance.

\section{The Product Realization Chain As A Control SYSTEM?}

To analyze and further understand product realization, we consider each block of the chain as a black box. Considered in this light, we enable a modeling approach by taking under account the input and the output for each case.

The first block of product realization is the product design. The input in this case is the effort of the design team. This effort is reflected upon the output that is usually a product prototype or the number of design specification. Assuming a constant amount of effort during the design stage, arising from number of people and the man-hours, we concern the input as a step function. The step response in this case is the percentage of final product specifications that appear in the end of this phase. Taking into account that the design of a new product is a learning process and gradually builds results, the output is considered as an exponential function of specification percentage over time.

The second block of product realization receives as input these product specifications and develops the process specifications for the manufacturing department to follow. Similarly, we assume as input a step function; the amount of product specifications that process engineers receive to establish a new production process. Since process design gradually builds results too, the output will be the step response depicted as an exponential function of process/manufacturing specifications percentage.

Finally the last stage of product realization chain is the actual execution of the production process. This stage is a download of instructional information to physical materials. The manufacturing department receives the total manufacturing specifications, built during the previous stage. As a result, the input is a step response of the process specifications, while the 

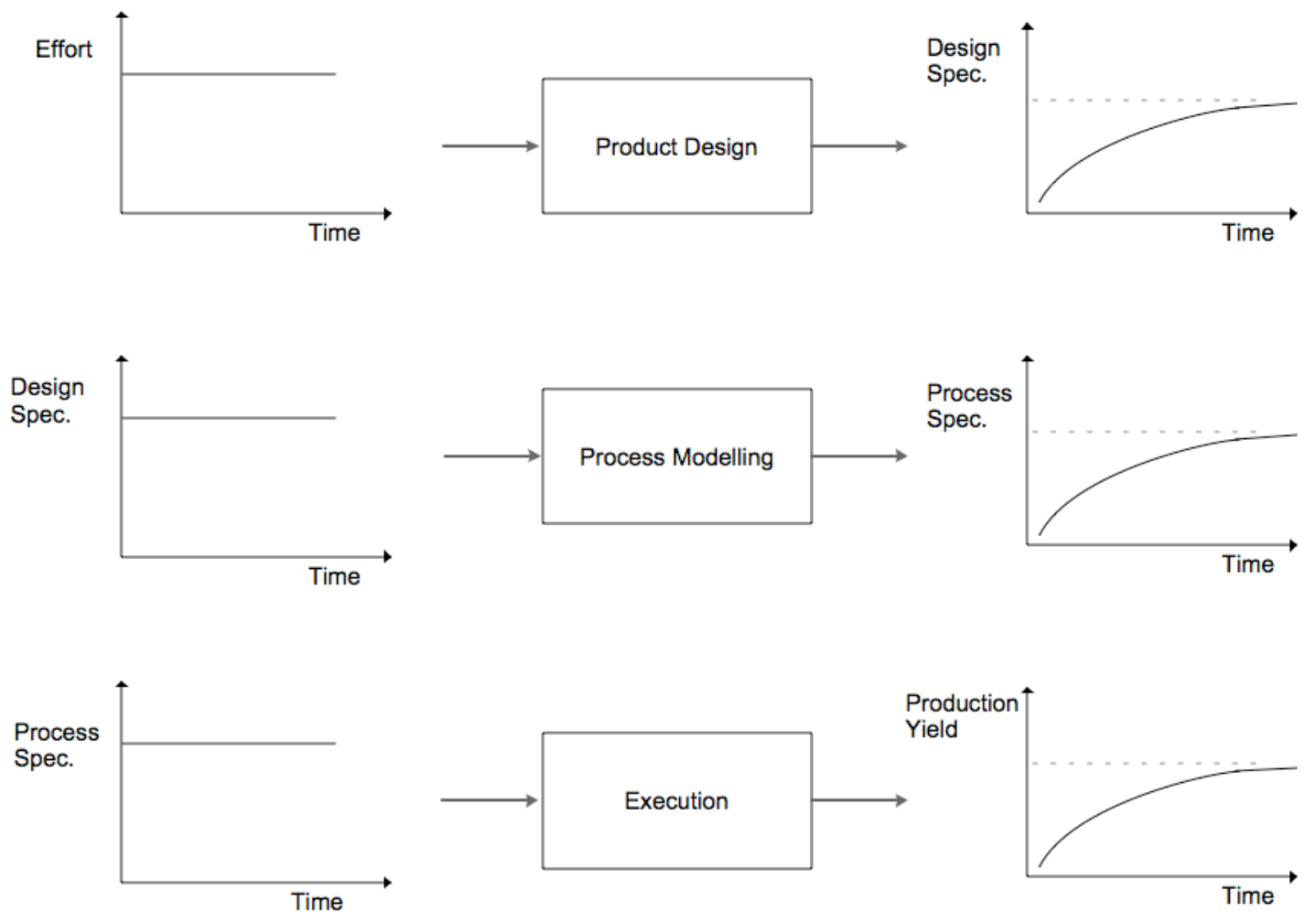

Figure 2. Product realization chain block modeling

output is an exponential function of production yield. Due to the learning curve during the process execution, productivity grows gradually until a certain capability level that is considered the steady state.

Figure 2 presents the step function input and the step response output of each block of the product realization chain.

Considering that each block represents a transfer function, the next stage is to aggregate the building blocks, in order to develop the transfer function for the whole system and acquire the overall response curve that represents learning.
In the next section, we present an empirical case study on the Ipod and the learning process that took place during its development to clarify the presented concept.

\section{THE IPOD REALIZATION CHAIN}

\section{A. Case study}

The iPod revolutionized the $\mathrm{mp} 3$ player market and transformed the digital music industry forever. Through this case study we approach the proposed learning framework and the product realization chain behind the iPod, in order to detect

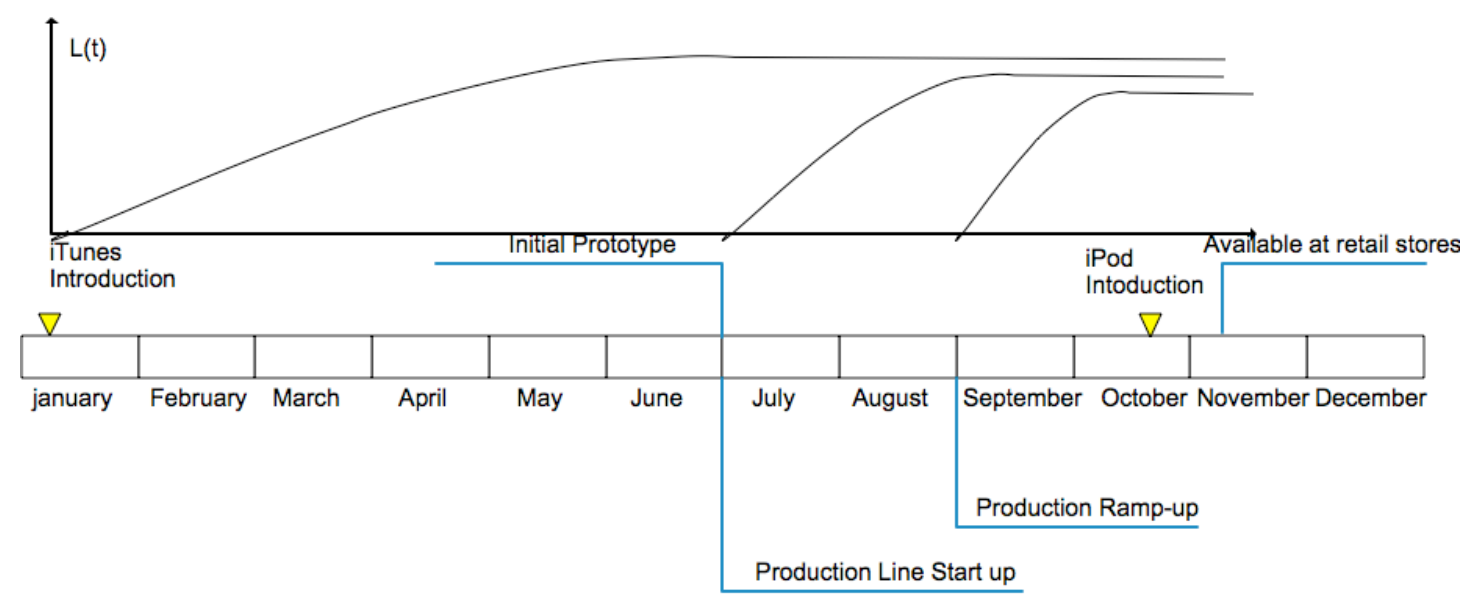

Figure 3. IPod development timeline 
the characteristics of each development stage in the product timeline.

Apple in January 2001 introduced the iTunes software. Since iTunes was just the foundation software, clearly the introduction of a digital music player was the next big step. The challenge for Apple was to transform this concept to an actual product in a year.

IPod originated with a business idea by Tony Fadell, an independent contractor who was a former employee of General Magic and Phillips [10]. Fadwell was a hardware expert developing handheld devices, envisioned a brand new small hard drive-based player with a Napster music sale service to complement it [11]. Apple was working independently with Fadell but hired him in April 2001 to run the iPod and Special Projects Department and assigned him a typical industrial design team of about 30 people [11]. Fadell was familiar with PortalPlayer a fables semiconductor company, founded in 1999. Apple was on a tight schedule and the fact that PortalPlayer had a reference design, about 80 percent complete [11], [12] was very attractive for Apple. They already had an operating system, the software and hardware. Consequently, the iPod relied on a reference design by PortalPlayer [10, 11, 12]. However the key members of the design chain included
Sony, Wolfson, Toshiba and Texas Instruments [12].

The new interface was designed in-house for Apple in about three months. In July 2001 a primary prototype was ready, with the new user interface $[11,13]$.

The production lines had begun set-up by Foxconn, but a problem with the battery power management arisen cutting down the battery life to three hours [10] [11]. The problem was fixed and after 8 weeks the production starts to ramp-up [11].

A press event in 23rd of October introduced the product and iPod hit the stores at 10 November 2001. Until the end of the year 125.000 units were sold [12].

The iPod came together in somewhere between six and nine months, from concept to market, and its coherence as a product given the time frame and the number of variables is astonishing. Apple's designers managed this by mimicking the manufacturing during prototyping; spending most of their time working with manufacturing and figuring out how to implement their ideas.

Concluding, the initial product design phase for iPod took 6 months to transform the concept to an initial prototype. The process modeling and set-up of the production facility lasted

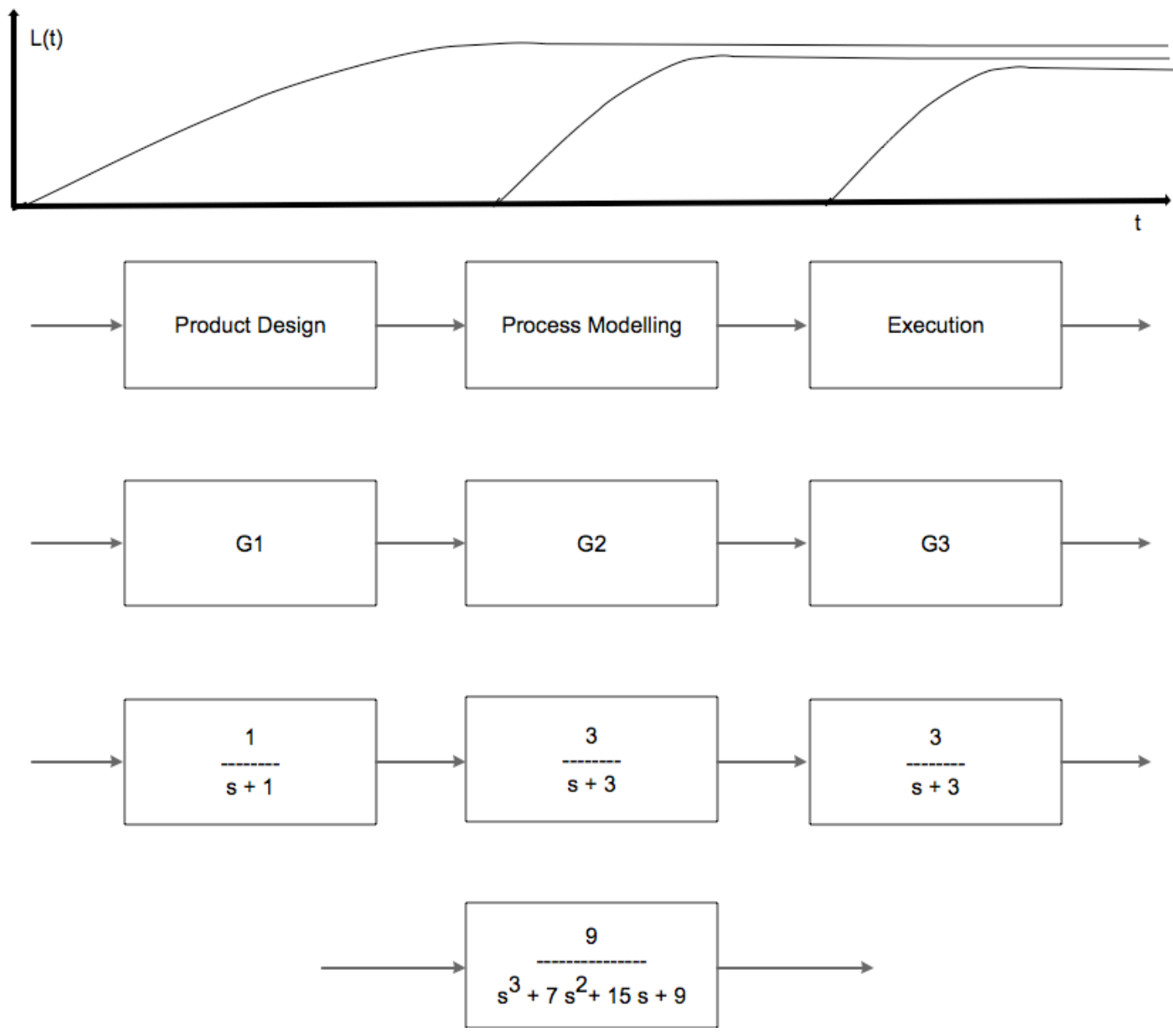

Figure 4. The IPod Transfer Function 
about 2 months. Finally the production ramp-up began two months before the release of the products to retail shops.

\section{B. Model Building}

According to the timeline presented in the previous section, the learning modeling during the iPod realization chain are developed.

MatLab software enables modeling the realization chain blocks as the blocks G1, G2, G3. The transfer functions in figure 5 were acquired giving an input of steady state in step response after six, two and two months respectively according to the development moths of our case study. Finally, through control system theory we are able to aggregate these block transfer functions and result the overall system transfer function. Figure 6 presents the system's step response that is the final learning curve of the whole iPod development.

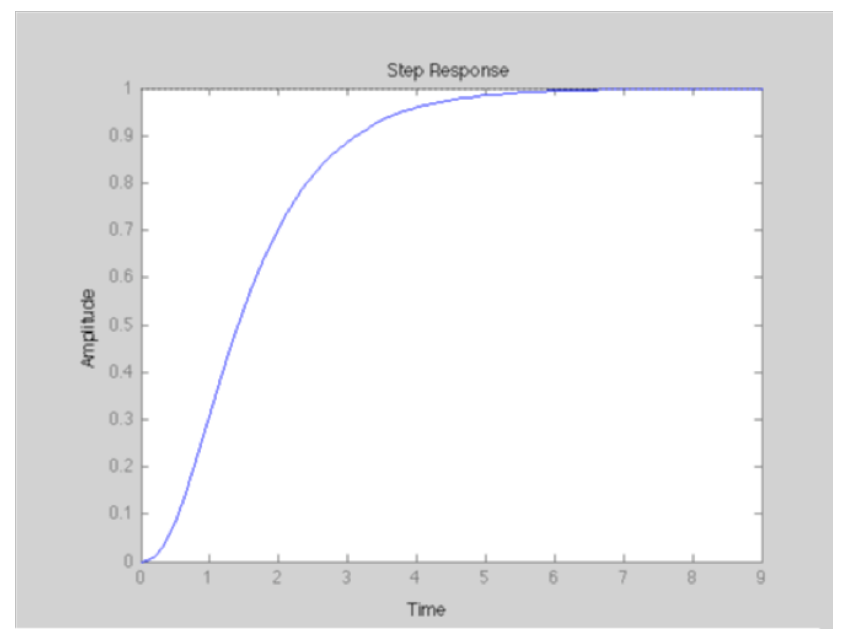

Figure 5. IPod product realization chain step response

\section{CONCLUSIONS}

There is a strong analogy between Darwin's quote and today's market climate. It is not the strongest of the species that survives, nor the most intelligent, but the one most adaptable to change. Accordingly, to survive for firms, is to learn quickly and adapt.

However, adaptability is a dimensionless value when it comes to business activities. For learning on the other hand, despite the large body of literature on learning curves, there is no known unifying framework able to monitor and analyze the whole process of product realization as a holistic learning process.

In this paper we attempt to build a unifying learning framework, taking under consideration the dynamics of each function during new product development. Treating the product realization chain as a control system, we are able to track down and measure inputs and outputs that allow us to model each phase individually. Furthermore, we are able to aggregate the component functions and develop the entire system transfer function, in order to acquire the learning curve of the product realization chain.

This basic premise of this methodology is initially vetted in Apple's IPod realization chain that is considered to be one a highly innovative product that today counts six generations.

Future work should focus upon the role of learning in each particular stage of product realization, investigating the complex underlying dynamics that occur in order to develop a more sophisticated modeling of learning processes during new product development.

\section{REFERENCES}

[1] Wright, T. P. "Factors Affecting the Cost of Airplanes," Journal of the Aeronautical Sciences, vol. 3, pp. 122-128, 1936.

[2] Krishnan, V. and Ulrich, K. T. "Product development decisions: A review of the literature," Management Science, vol. 47, no. 1, pp. 1-21, 2002.

[3] Terwiesch, C., Xu, Y. "The copy-exactly ramp-up strategy: Trading-off learning with process change," IEEE Transactions on Engineering Management, vol. 51, no. 1, pp. 70-84, 2004.

[4] Fjällström, S., Säfsten, K., Harlin, U., and Stahre, J. "Information enabling production ramp-up," Journal of Manufacturing Technology Management, vol. 20, no. 2, pp. 178-196, 2009.

[5] Brooker, J. D., Swift, K. G., Brown, N. J., "Design for assembly quality: strategies, guidelines and techniques," Journal of Engineering Design, vol. 16, no. 3, pp. 279-295, 2005.

[6] Pisano, G.P., "The Development Factory: Unlocking the Potential of Process Innovation", Harvard Business School Press, Boston, MA, 1997.

[7] Lu, Q. and Botha, B. "Process development: a theoretical framework", International Journal of Production Research, Vol. 44, No. 15, 2006, pp. 2977-2996

[8] Fujimoto, T., "Comparing performance and organization of product development across firms, regions, and industries: the applicability of the automobile case", in Eto, H. (Ed.), R\&D Strategies in Japan: The National, Regional, and Corporate Approach, Elsevier, New York, NY,

[9] Lu, Q. and Wood, L., "The refinement of Design For Manufacture: inclusion of process design," International Journal of Operations and Production Management, vol. 26, no 10, pp. 1123 - 1145, 2006

[10] Hormby, T. and Knight D., "A history of the IPod:200 - 2004," Low end MAC, http://lowendmac.com/orchard/05/origin-of-the-ipod.html, 2007

[11] Kahney, L. "Inside look at birth of the IPod", Wired Magazine, http://www.wired.com/gadgets/mac/news/2004/07/64286, 2004

[12] Sherman, E. "Inside the Apple iPod design triumph," Electronics Design Chain Magazine, http://www.designchain.com/coverstory.asp?issue=summer02, 2002

[13] Kahney, L. "Straight Dope on the IPod's Birth,” Wired Magazine, http://www.wired.com/gadgets/mac/commentary/cultofmac/2006/10/719 56,2006 